RESEARCH PAPER RP735

Part of Journal of Research of the National Bureau of Standards, Volume 13, November 1934

\title{
FREEZING POINT OF GALLIUM
}

\author{
By Wm. F. Roeser and James I. Hoffman
}

\section{ABSTRACT}

The temperature of equilibrium between liquid and solid gallium was found to be $29.780 \pm 0.005^{\circ} \mathrm{C}$. Four determinations on two different lots of metal all yielded the same result. Difficulties ascribed to the undercooling and low thermal conductivity of the gallium prevented a satisfactory determination from ordinary heating and cooling curves. The temperature of equilibrium between the liquid and solid phases of the metal was obtained by measuring the temperature of an intimate mixture of the solid and the liquid. It was found that the presence of the oxide did not affect the freezing temperature, indicating that the oxide is not appreciably soluble in the metal.

\section{CONTENTS}

I. Introduction

II. Present work

1. Preliminary discussion

2. Procedure

3. Results

III. Summary of previous work

\section{INTRODUCTION}

The preparation by one of the authors ${ }^{1}$ of a considerable quantity of gallium of exceptional purity afforded an opportunity of determining the melting or freezing temperature of this metal. Variations in the values previously determined suggest that impure metal was used in some of these cases, or that experimental difficulties have resulted in errors many times larger than those which can be ascribed to temperature measurements.

The usual method of determining the temperature of equilibrium between the liquid and solid phases of a metal is to immerse the actuating element of a thermometric device in the material and use. the absorption or evolution of heat as a criterion of the change in state. However, in reviewing the literature only one determination ${ }^{2}$ was found in which this method was used. In this case, the bulb of a liquid-in-glass thermometer was immersed in the gallium and the melting temperature obtained by running heating curves. In the other determinations, the temperature of a bath was measured at the time a sample of the metal in the bath was observed to melt, or at the time melting or freezing was indicated by the contraction or expansion of the metal in a dilatometer.

1 J. Research NBS 13,665(1934)RP734.

2 T. W. Richards and S. Boyer, J. Am. Chem. Soc. 43,274(1921) 


\section{PRESENT WORK}

\section{PRELIMINARY DISCUSSION}

In the present work it was found that the usual method of determining the freezing temperature from time-temperature cooling curves did not give satisfactory results. The difficulties encountered in these attempts to obtain the freezing temperature from cooling curves are ascribed to the extreme undercooling and apparently low thermal conductivity of gallium. In running an ordinary cooling curve the liquid gallium undercooled ${ }^{3}$ as much as $15^{\circ} \mathrm{C}$. When the liquid gallium was brought to a temperature below its freezing point and crystallization was started by adding a crystal of the pure metal, freezing proceeded slowly from the added solid, while the liquid apparently remained in an undercooled state. The temperature in various parts of the liquid depended upon the distance from the solid and upon the temperature of the bath. Similar difficulties may account for the fact that no determinations using cooling curves were found in the literature.

No attempt was made to obtain heating curves as it was believed that they would not have given very satisfactory results because of the apparently low thermal conductivity of gallium.

\section{PROCEDURE}

The procedure followed in the present work was only slightly different from the usual method of running heating and cooling curves. The crystals of gallium were placed in a pyrex-glass tube having an inside diameter of about $1 \mathrm{~cm}$. To prevent the loss of gallium in case the tube should break and to reduce the rate of heat transfer, the pyrex tube was placed inside a slightly larger glass tube. After the gallium was melted, the assembly was placed in a stirred water bath controlled at a temperature of about $29.5^{\circ} \mathrm{C}$. Crystallization was started by adding several crystals of gallium which were stirred into the liquid. A five-junction copper-constantan thermocouple, protected by a small thin-wall pyrex-glass tube, was immersed in the gallium to the desired depth and held in place by means of corks. The temperature of the bath was maintained below the freezing point until about onehalf of the metal was frozen. The emf of the thermocouple in the gallium was then measured both when the bath was adjusted to the same temperature as that of the gallium and as the temperature of the bath was varied above and below that of the gallium. It was found that the temperature of the gallium was constant to $0.0005^{\circ} \mathrm{C}$ (the precision of the measurements) while the temperature of the bath was raised and lowered nearly a tenth of a degree above and below the temperature of the gallium. The temperature of the bath was maintained both above and below the freezing temperature for at least an hour without any change in the temperature of the metal. This constant temperature was taken as the temperature of equilibrium between liquid and solid gallium.

The temperature corresponding to the observed emf of the thermocouple at the freezing point was determined after each series of measure-

3 This is not in agreement with the statement "It was found that gallium when quite pure shows little of the tendency toward supercooling which is so characteristio of impure gallium", by W. M. Craig and G. W. Drake, J .Am. Chem. Soc. $56,584(1934)$. 
ments. The thermocouple was placed in the bath which was completely surrounded by a thermostated water jacket, and the temperature adjusted until the thermocouple yielded the same emf as obtained when immersed in the gallium during freezing and melting. The temperature of the bath, and consequently the freezing point of the gallium, was then measured with a standard platinum resistance thermometer. The freezing temperature was thus referred to the international temperature scale. We are indebted to R.S. Jessup for the calorimeter used as a bath and for assistance in controlling and measuring the temperatures.

The first two determinations were made on a 15-g portion of gallium prepared from crude metal from Bartlesville, Okla. During the first determination, no precautions were taken to prevent the metal from oxidizing, and consequently an appreciable amount of oxide was present. The second determination was made on the same lot of metal after the oxide had been remored. The oxide was dissolved by shaking the molten metal in the glass tube with dilute hydrochloric acid. As soon as the metal appeared clean and bright, the acid was decanted and replaced by recently boiled water. The protecting layer of water which contained a trace of acid prevented oxidation of the metal during the determination.

In order to ascertain whether the heat of reaction between the trace of acid remaining in the protecting solution and the gallium had an appreciable effect on the temperature measurement, the difference between the temperature of the bath and that of the liquid metal covered with the protecting solution was measured when the bath was maintained at a constant temperature above the freezing point of the gallium. The temperature of the metal under these conditions was less than $0.003^{\circ} \mathrm{C}$ higher than that of the bath.

The other two determinations were made on a $35-\mathrm{g}$ portion of gallium in order to obtain a greater depth of immersion of the thermocouple. This metal was prepared from impure gallium originating from many different sources. The first determination was made after the oxide had been removed from the metal with hydrochloric acid as previously described, and the other on the same metal after removing the oxide and then replacing the hydrochloric acid with liquid petrolatum.

\section{RESULTS}

Each of the 4 separate determinations on the 2 different lots of metal yielded the same result, $29.780^{\circ} \mathrm{C}$, for the temperature of equilibrium between liquid and solid gallium. The uncertainty in this determination is believed to be not greater than $\pm 0.005^{\circ} \mathrm{C}$. The fact that the presence of oxide did not affect the results indicates that the oxide is insoluble in the metal.

It is estimated that the gallium on which these determinations were made contained less than 0.001 percent of impurities. The preparation and purity are discussed elsewhere in this journal, Research Paper RP 734. Spectrochemical tests indicated that no contamination occurred during the freezing point determinations. 


\section{SUMMARY OF PREVIOUS WORK}

The various determinations of the melting point of gallium found in the literature together with the value reported in this paper are summarized in table 1.

TABLE 1.-Determinations of the melting point of gallium

\begin{tabular}{|c|c|c|c|}
\hline Author & References & Methods used & $\begin{array}{c}\text { Re- } \\
\text { ported } \\
\text { values }\end{array}$ \\
\hline $\mathrm{de} B$ & Comnt rend 8?.1036(18 & Net given & ${ }^{\circ} \mathrm{C}$ \\
\hline Do & Compt. rend. 83, 611(1876) & 19ut given-..- & 30.15 \\
\hline $\begin{array}{l}\text { A. Guntz and W. Broniew- } \\
\text { ski. }\end{array}$ & Compt. rend. 147, 1474(1908) & $\begin{array}{l}\text { Measured change in specific resist- } \\
\text { ance. }\end{array}$ & 29 \\
\hline $\begin{array}{l}\text { P. E. Browning and H. S. } \\
\text { Uhler. }\end{array}$ & Am. J. Sci. 41, 351(1916) & $\begin{array}{l}\text { Observed temperature at which a } \\
\text { disk of gallium fell through a plati- } \\
\text { num ring. }\end{array}$ & 29.5 \\
\hline $\begin{array}{l}\text { T. W. Richards and } \mathrm{S} \text {. } \\
\text { Boyer. }\end{array}$ & J. Am. Chem. Soc. 41, 133(1919)_- & $\begin{array}{l}\text { Observed crystal at bottom of a test } \\
\text { tube or suspended in a ring. }\end{array}$ & 30.8 \\
\hline $\begin{array}{l}\text { Boyer, reported by } \\
\text { P.W. Bridgman. }\end{array}$ & Contrib. Jeff. Phys. Lab. 14, & Not given & 29.85 \\
\hline T. W. Richards and S. & J. Am. Chem. Soc. 43, 274(1921)- & $\begin{array}{l}\text { Heating curves; thermometer with } \\
\text { small Beckmann apparatus. }\end{array}$ & 29.752 \\
\hline $\begin{array}{l}\text { W. M. Craig and G. W. } \\
\text { Drake. }\end{array}$ & $\begin{array}{l}\text { J. Am. Chem. Soc. 43, 274(1921)- } \\
\text { J. Am. Chem. Soc. 56, 584(1934)- }\end{array}$ & Dilatometer & $\begin{array}{l}29.75 \\
29.755\end{array}$ \\
\hline $\begin{array}{l}\text { W. F. Roeser and J. I. } \\
\text { Hoffman. }\end{array}$ & Present work & $\begin{array}{l}\text { Temperature of equilibrium be- } \\
\text { tween solid and liquid. }\end{array}$ & 29.780 \\
\hline
\end{tabular}

Washington, September 14, 1934. 